\title{
Characteristics of daily extreme wind gusts on the Qinghai-Tibet Plateau, China
}

\author{
YAO Zhengyi ${ }^{1}$, LI Xiaoying ${ }^{1}$, XIAO Jianhua ${ }^{1,2^{*}}$ \\ ${ }^{1}$ Key Laboratory of Desert and Desertification, Northwest Institute of Eco-Environment and Resources, Chinese Academy of \\ Sciences, Lanzhou 730000, China; \\ ${ }^{2}$ Gansu Center for Sand Hazard Reduction Engineering and Technology, Lanzhou 730000, China
}

\begin{abstract}
Severe wind is a major natural hazard and a main driver of desertification on the Qinghai-Tibet Plateau. Generally, studies of Qinghai-Tibet Plateau's wind climatology focus on mean wind speeds and its gust speeds have been seldom investigated. Here, we used observed daily maximum gust speeds from a 95station network over a 5-year period (2008-2012) to analyze the characteristics of extreme wind speeds and directions by fitting Weibull and Gumbel distributions. The results indicated the spatial distribution of extreme wind speeds and their direction on the Qinghai-Tibet Plateau is highly variable, with its western portion prone to greater mean speeds of extreme wind gusts than its eastern portion. Maximum extreme wind speeds of 30.9, 33.0, and $32.2 \mathrm{~m} / \mathrm{s}$ were recorded at three stations along the Qinghai Tibet Railway. Severe winds occurred mostly from November to April, caused primarily by the westerly jet stream. Terrain greatly enhances the wind speeds. Our spatial analysis of wind speed data showed that the wind speeds increased exponentially with an increasing altitude. We also assessed the local wind hazard by calculating the return periods of maximum wind gusts from the observational data based on the statistical extreme value distributions of these wind speeds. Further attention should be given to those stations where the yearly maximum daily extreme wind speed increased at a rate greater than that of mean value of daily extreme wind speeds. Severe extreme wind events in these regions of the plateau are likely to become more frequent. Consequently, building structural designers working in these areas should use updated extreme wind data rather than relying on past data alone.
\end{abstract}

Keywords: extreme wind gusts; wind direction; wind hazard; wind speeds; Qinghai-Tibet Plateau

Citation: YAO Zhengyi, LI Xiaoying, XIAO Jianhua. 2018. Characteristics of daily extreme wind gusts on the QinghaiTibet Plateau, China. Journal of Arid Land, 10(5): 673-685. https://doi.org/ 10.1007/s40333-018-0094-y

\section{Introduction}

Weather-related disasters in China have resulted in large economic losses. Extreme wind events, such as tropical cyclones and severe storms, have caused extensive damage to the country's southeastern coastal regions and urban communities (Shi, 2003; Chen and Gao, 2010); likewise, severe wind events can adversely affect the Qinghai-Tibet Plateau (QTP) (Luo et al., 2012) and threaten the Qinghai-Tibet Railway. While the railway's sand control system, consisting of sand fences and barriers, can retain sand transported by very strong winds, over time these winds often destroy the sand control infrastructure (Bai et al., 2005; Zhang et al., 2010; Li et al., 2015).

The impact of windstorms on the QTP is significant, and the economic losses incurred there due

*Corresponding author: XIAO Jianhua (E-mail: xiaojh@1zb.ac.cn)

Received 2017-02-23; revised 2017-11-16; accepted 2017-11-30

C Xinjiang Institute of Ecology and Geography, Chinese Academy of Sciences, Science Press and Springer-Verlag GmbH Germany, part of Springer Nature 2018 
to extreme wind events are considerably higher than those from other natural hazards. Strong winds in winter or spring often result in blizzards in the middle and eastern portions of the QTP, where the blowing snow leads to low visibility, road closures, livestock deaths, and the destruction of housing. A severe blizzard on 25 May 1989 trapped 27,800 gold miners in the Hoh Xil Region, resulting in 42 deaths (Ju, 2012). The sustained winds of the QTP have led to the construction there of many wind farms able to generate clean, renewable energy. But because severe winds can damage wind turbines, when local wind speeds exceed $25 \mathrm{~m} / \mathrm{s}$, the turbines are shut off (Larsson, 2002; Datta and Ranganathan, 2003). Severe wind also is the main driver of desertification on the QTP. The strong winds severely erode the loose, dry grassland, leading to frequent sand storms and extensive desertification (Xie et al., 2015). Dust storms caused by the QTP's severe winds also contribute to the East Asian dust phenomenon (Fang et al., 2004; Han et al., 2008; Zhou et al., 2015).

The surface mean wind regime of the QTP is reasonably well documented, but published information on its observed extreme wind speeds remains rather sparse. Research into the differences between mean wind speeds and gust speeds is thus needed. Local gust speed characteristics can directly impact wind energy generation, aviation, railways, highways, and structural design, and are relevant to studies on the effects of wind-driven blizzards and dust storms. Accurate knowledge of the frequency distribution of strong surface winds, particularly of wind gusts, is crucial for many safety, engineering, and financial applications.

Our study is concerned primarily with the characteristics of daily extreme wind speeds on the QTP. We summarized the frequency distributions of its extreme wind speeds, wind directions, and distributions. Using the Gumbel distribution, we analyzed the probability of extreme wind speeds and discuss the effects of topography on extreme winds. Finally, we identified and quantified interand intra-annual temporal and spatial variations in gust speeds.

\section{Materials and methods}

\subsection{Study area}

The QTP is the world's highest and largest plateau. With an average elevation exceeding $4000 \mathrm{~m}$, it has been described as "the roof of the world" and as the third polar region (Qiu, 2008). The QTP is the source of headwaters for most of the major rivers in the surrounding regions, namely the Yellow River and the Yangtze River, and the Mekong, Salween, Irrawaddy, Brahmaputra, Ganges, and Indus Rivers. Its glaciers store water and maintain water flow into these river basins.

The QTP's topography varies greatly, from high mountains down to large alluvial plains, rolling lands, and low-lying basins. The QTP is not only the highest desert in the world but also one of the coldest, with average temperatures ranging from $-5.1^{\circ} \mathrm{C}$ to $14.8^{\circ} \mathrm{C}$ in the east, and from $6.9^{\circ} \mathrm{C}$ to $7.8^{\circ} \mathrm{C}$ in the west. Precipitation varies regionally more than does temperature. The long-term (1981-2010) average rainfall on the QTP ranges from 15.5 to $922.6 \mathrm{~mm}$, over $50 \%-60 \%$ of which falls in the spring-summer months (April to August). The annual average wind speeds range from 0.9 to $5.0 \mathrm{~m} / \mathrm{s}$; the frequency of gales with wind velocities greater than $17.2 \mathrm{~m} / \mathrm{s} \mathrm{ranges}$ from 1.2 to $162 \mathrm{~d}$ per year; and on average, dust storms occur on 0 to $12.4 \mathrm{~d}$ per year.

\subsection{Wind data}

We analyzed daily extreme wind speeds (i.e., one value recorded per day, typically measured over 3 seconds), defined by the World Meteorological Organization as the maximum instantaneous wind speeds in a calendar day (i.e., from 00:00 to 24:00 LST).

Our data sources for daily extreme wind observations (measured at the standard 10-m height) were from 95 meteorological stations on the QTP (Fig. 1). Although hourly mean wind speeds have been recorded for some time now, 58 stations have recorded daily extreme wind gust data only since 2004; another 10 stations have such data since 2006, and the remaining 27 stations have it from 2007 onward. We obtained all this data from the China Meteorological Data Service Center. However, because the time-span for the available extreme wind data was not uniform, we used the 
more complete dataset from 2008 to 2012 to analyze the spatial variation and direction of wind.

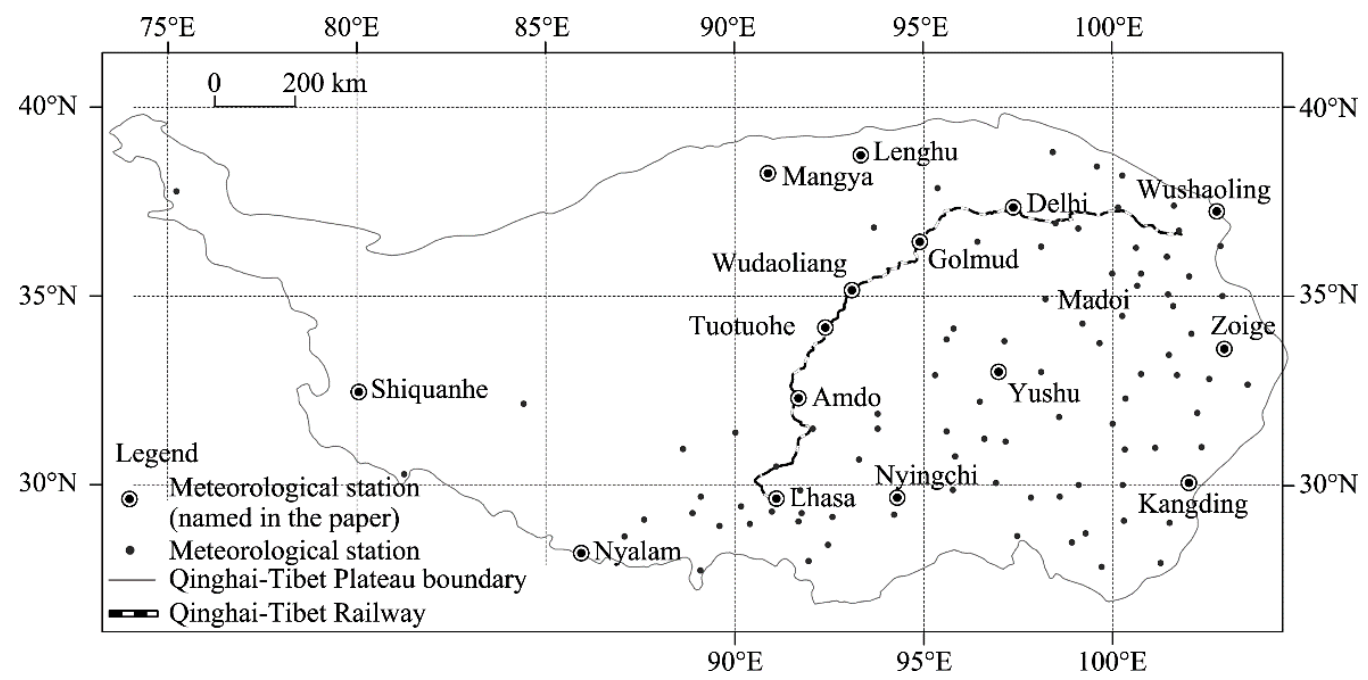

Fig. 1 Locations of the 95 meteorological stations and the Qinghai-Tibet Railway

Prior to our analysis, we checked the data for its quality. This step is important to perform because the statistical analysis requires that the measurement series be homogeneous. In particular, there should not be any non-climatic trends (e.g., due to changes in measurement methods or in measurement conditions), no inconsistent values (e.g., unrealistic wind peaks), and no long gaps in the data. We visually inspected the time series by considering three parameters: daily extreme wind speed, daily maximum 10-minute wind speed, and daily mean wind speed. To create a representative data set, we replaced erroneous or missing data points at each meteorological station by interpolating. For example, a linear regression exists between daily extreme wind speed and daily maximum wind speed (10-min mean wind speed) for the data of 2008-2012. Thus, we calculated the missing daily extreme wind speed data $(<1 \%$ of the sample) using this regression.

We analyzed the wind speeds frequency distribution using the Weibull distribution and the probability of extreme wind speeds using the Gumbel distribution. We also obtained data from another 40 stations near the QTP and incorporated their data into the isoline maps for annual mean wind speeds using Arcview v.3.2 (ESRI, USA). We reviewed all the data for accuracy and removed any outliers, yielding a robust dataset for analysis and inference.

\subsection{Weibull distribution}

Interest in the frequency distribution of near-surface wind speeds has grown as a result of increasing wind energy generation and associated structural safety design issues (Seguro and Lambert, 2000; Carta and Ramírez, 2007; Carta et al., 2009; Rocha et al., 2012). The Weibull distribution provides a good analytical approximation to the cumulative distribution and is particularly useful for obtaining the $90 \%-99 \%$ thresholds (Stewart and Essenwanger, 1978; Monahan, 2007; Kiss and Jánosi, 2008; Tye et al., 2014).

The Weibull distribution is typically used to develop an appropriate power-law transfer function between modeled and observed wind speeds for mapping. Stewart and Essenwanger (1978) showed that a three-parameter model is better than a two-parameter model for predicting extreme values. Importantly, the three-parameter Weibull function provides a convenient representation of the wind speed data for wind energy calculation purposes (Seguro and Lambert, 2000). The Weibull probability density function has this formula:

$$
f(x)=\frac{\alpha}{\beta}\left(\frac{x-\gamma}{\beta}\right)^{\alpha-1} \exp \left[-\left(\frac{x-\gamma}{\beta}\right)^{\alpha}\right],(x \geq \gamma),
$$

where $\alpha$ is the shape parameter (dimensionless), $\beta$ is the scale parameter $(\mathrm{m} / \mathrm{s})$, and $\gamma$ is the location 
parameter $(\mathrm{m} / \mathrm{s})$. In the case of $\gamma=0$, a two-parameter version of the distribution is obtained. Several methods are available for calculating $\alpha$ and $\beta$ (Lun and Lam, 2000; Razali et al., 2009).

The mean and variance of the Weibull distribution are computed using the gamma distribution. The mean of the Weibull distribution is calculated as follows:

$$
\bar{x}=\beta \times \Gamma\left(1+\frac{1}{\alpha}\right),
$$

where $\Gamma$ represents the gamma function.

We used the Weibull distribution as a model function for a regression analysis of wind speed distribution. For this analysis, we first generated a frequency distribution of the wind speed data, with speeds classed in 1-m/s increments for winds in all directions. We then fitted a model curve to this distribution and applied two parametric models for the unimodal distributions. The mean absolute error (Err) is defined as follows:

$$
\operatorname{Err}=\sum_{i=1}^{n}\left(x_{i}-f_{i}\right)^{2}
$$

where $x_{i}$ and $f_{i}$ are the measured data and the modeled results, respectively. This measure of deviance can be used to show which model has a better fit to the data.

\subsection{Gumbel distribution}

In probability theory and statistics, the Gumbel distribution is used to model the distribution of the maximum (or minimum) of a number of samples of various distributions. It is useful for predicting the chance whether an extreme earthquake, flood, or other natural disaster, will occur (Waylen and Woo, 1982). The potential applicability of the Gumbel distribution to represent the distribution of maxima relates to extreme value theory, which indicates that it is likely to be useful if the distribution of the underlying sample data is of the normal or exponential type. A probability distribution function can yield the expected meteorological conditions within a given time period (return periods) in the future.

In our study, Gumbel's extreme value distribution function (Goldstein et al., 2008; Morjani, 2011) was the most appropriate function to use, because it seeks to identify the temporal distribution of extreme values for various return periods. Additionally, this probability distribution function is one of the most widely used for extreme value prediction when analyzing hydrological and meteorological data (Morjani, 2011):

$$
F(x)=\mathrm{e}^{-\frac{x-a}{b}},
$$

where $F(x)$ is the cumulative distribution function; $a$ is a location parameter; and $b$ is a scale parameter and the adjustment parameter.

Replacing $(x-a) / b$ with the reduced variant $u$, the cumulative distribution function becomes

$$
F(x)=\mathrm{e}^{-\mathrm{e}^{-u}} \rightarrow u=-\ln [-\ln F(x)]=-\ln \left[-\ln \left(1-\frac{1}{T}\right)\right],
$$

where $F(x)=1-\frac{1}{T}$, and $T$ is the return period.

\section{Results}

\subsection{Wind climatology of the QTP}

The QTP's climate is jointly driven by the westerly circulation, South-Asian monsoon circulation, and QTP monsoon (Ye and Gao, 1979). However, a major geographical control on general circulation is the QTP itself: it influences the atmosphere in two ways: (1) By acting as a tall barrier, preventing the cold, dry air of the northern latitudes from entering the subcontinent and subduing the warm, moisture-laden winds from the oceans that drive the monsoon; and (2) By heating up during the summer and thus establishing an atmospheric circulation that is also conducive for the 
monsoon. When June begins, the subtropical jet stream disappears from the southern side of the QTP; this shift in the jet stream is associated with the slowing down of the Westerlies over the whole of Eurasia, but the QTP accentuates the northward displacement of jet stream. By contrast, the plateau is the most important factor driving the advance of the jet stream far south in midOctober. This abrupt onset of the summer monsoon at the start of June is promoted by the hydrodynamic effect in the Himalayas and not by the thermally induced low-pressure center over northwest India. The summertime heating of the QTP makes it a high-level heat source: a heat engine that produces a thermal anticyclone over this region in the middle part of the troposphere during the summer. Winds coming out of this anticyclone in a clockwise movement over the QTP give rise to easterly jet streams (flowing from east to west) on the southern side of this upper air anticyclone. These upper air easterlies then descend into the permanent high-pressure area formed over the southern Indian Ocean, intensifying the pre-existing high pressures. It is from this highpressure cell that the onshore winds start blowing towards the thermally induced low-pressure area developed in the northern Indian subcontinent. After crossing the equator, these surface winds change direction and become the South-Asian Monsoon (Boos and Kuang, 2010; Boos and Kuang, 2013; Liu and Dong, 2013).

\subsection{Spatial variation of extreme wind gusts}

Figure 2 shows the spatial distribution of mean daily extreme wind speeds during 2008-2012 on the QTP. The highest recorded gust speed in the 95-station monitoring network was $16.3 \mathrm{~m} / \mathrm{s}$ at a station in a north-south valley in the Himalayas; it formed from uplifting monsoonal air flowing from the Indian Ocean along the southern slope of the valley. The spatial distribution of extreme wind speeds and wind directions was highly variable on the QTP. Three stations along the QinghaiTibet Railway recorded high daily extreme wind speeds of $15.6 \mathrm{~m} / \mathrm{s}$ at Wudaoliang, $15.3 \mathrm{~m} / \mathrm{s}$ at Tuotuohe, and $14.7 \mathrm{~m} / \mathrm{s}$ at Amdo. The maximum extreme wind speeds at these three stations reached $30.9 \mathrm{~m} / \mathrm{s}$ at Wudaoliang, $33.0 \mathrm{~m} / \mathrm{s}$ at Tuotuohe, and $32.2 \mathrm{~m} / \mathrm{s}$ at Amdo. The geographic variation in extreme wind speeds indicated that higher gust speeds are recorded at stations located in southwestern QTP than in its eastern and southeastern areas. Statistical analyses revealed that the wind speeds increased exponentially with altitude (Fig. 3); this regression was significant $(P<0.01$, using an alpha level of 0.050$)$ and its adjusted $R^{2}$ of 0.522 was greater than that of the linear, logarithmic, or power regressions. However, some stations did deviate considerably from the fitted exponential curve, namely Nyalam, Wushaoling, Kangding, and Lenghu. These stations are located mainly at wind gaps, where the terrain enhances local wind speeds; omitting these improved the adjusted $R^{2}$ to 0.679 .

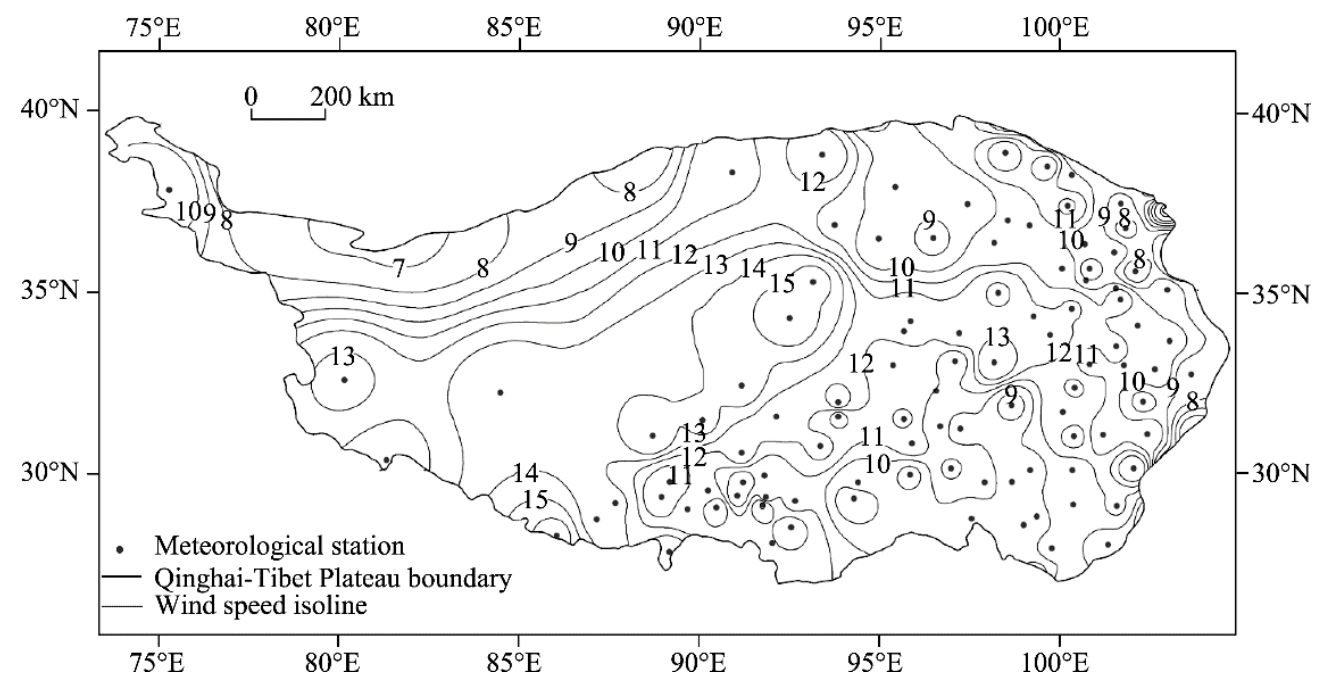

Fig. 2 Spatial distribution of mean daily extreme wind speed $(\mathrm{m} / \mathrm{s})$ 


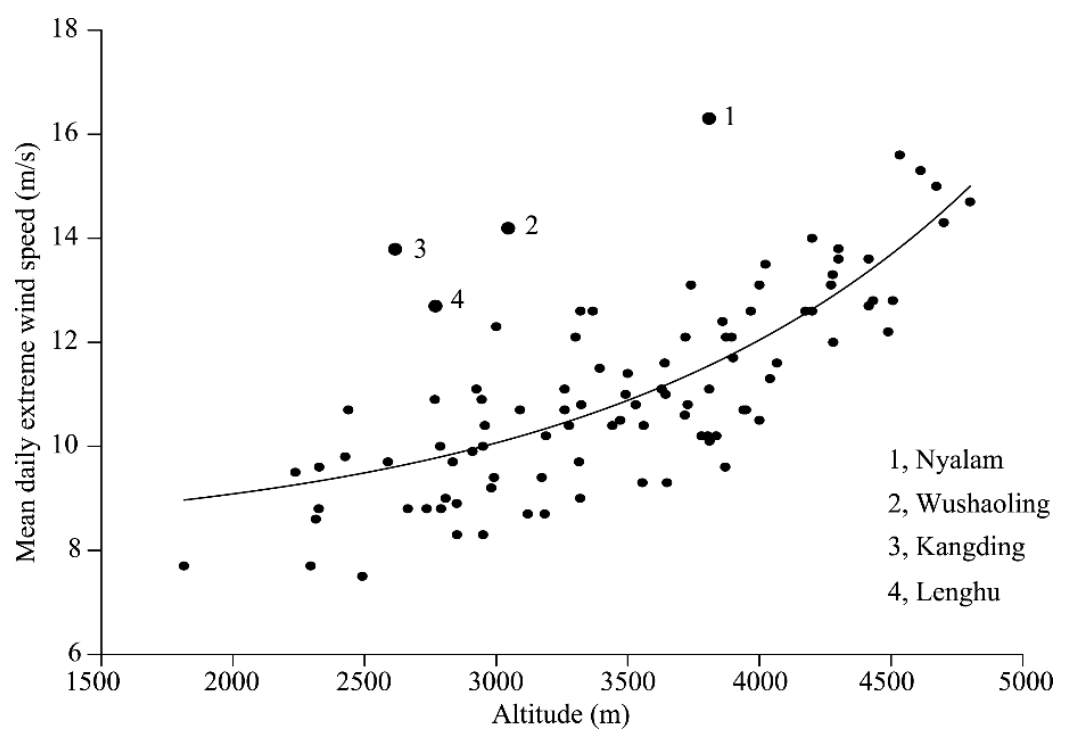

Fig. 3 Relationship between mean daily extreme wind speed and altitude on the Qinghai-Tibet Plateau (QTP)

Generally, the main wind direction of gusts coincided with the path of the westerly jet stream and the orientation of valleys and mountains (Fig. 4). In the middle and western portions of the QTP, the dominant winds are from the west and northwest, coinciding with the paths of the weather systems that influence this region. In southwestern QTP, the dominant wind comes from the southwest, coinciding with the paths of the South-Asian monsoon, although several stations did have a prevailing southeastern wind direction. In eastern and southeastern QTP the situation is more complicated, however. In southeastern Tibet and western Yunnan, the dominant wind is from the southeast while in western Sichuan it is from the northeast and east, with both following the paths of weather systems of the East-Asian monsoon.

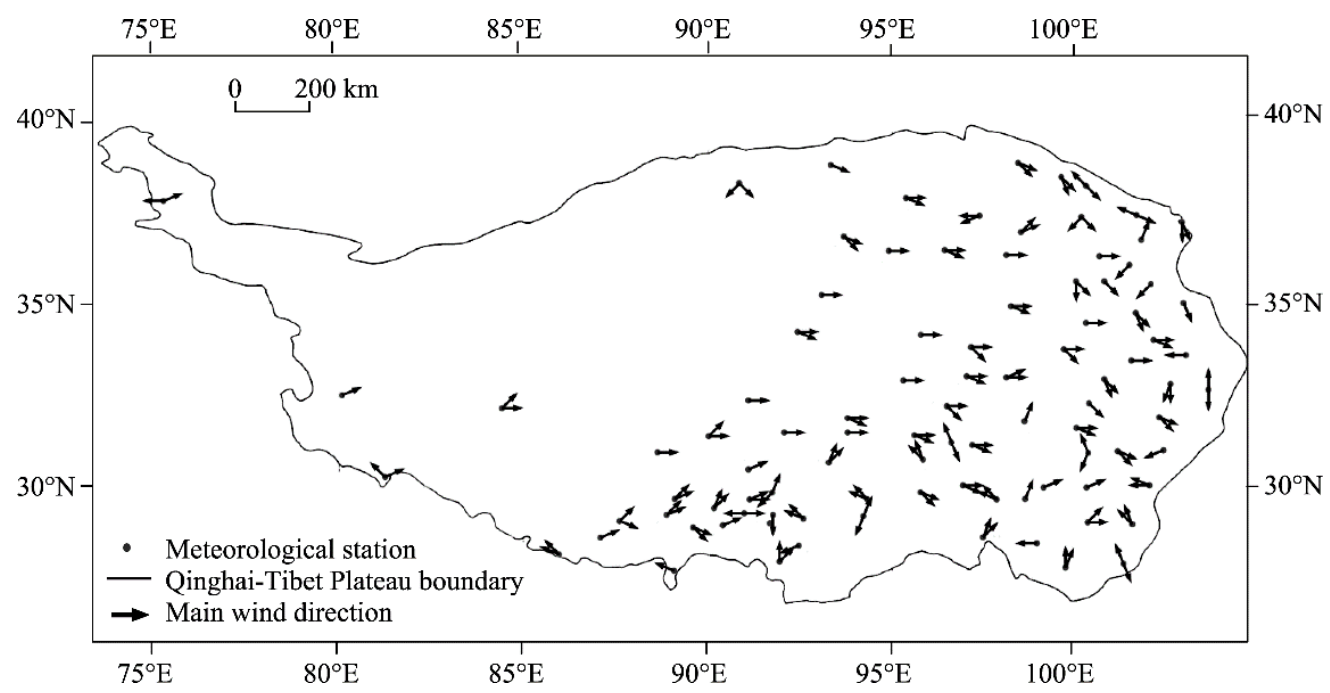

Fig. 4 Direction of dominant extreme wind gusts on the QTP

\subsection{Temporal variation in extreme wind gusts}

To assess inter-annual variation in extreme wind values across the network, we calculated the mean annual extreme wind for each station. Of the 95 stations analyzed, 46 showed a decrease whereas 39 stations showed an increase in wind speeds between 2004 and 2012, while 10 stations showed no obvious trend. 
The annually maximum value of daily extreme wind speeds exhibited an increasing trend at 44 stations and a decreasing one at 51 stations. Most stations, however, showed no significant correlation between their trends for mean value of daily extreme wind speeds and annually maximum value of daily extreme wind speeds. However, the top-10 daily extreme wind speeds at these stations displayed trends that were similar to the annually maximum value.

\subsection{Wind speed frequency distribution}

Figure 5 shows the frequency distributions of daily extreme wind speeds with fitted curves for 12 typical stations (classified at wind speed intervals of $1.0 \mathrm{~m} / \mathrm{s}$ ). Wudaoliang, Tuotuohe, and Amdo are located along the Qinghai-Tibet Railway and the Qinghai-Tibet Highway, where they are subject to extreme winds: maximum wind speeds reached above $32.0 \mathrm{~m} / \mathrm{s}$ and wind speeds $>17.2$ $\mathrm{m} / \mathrm{s}$ occurred $31.3 \%, 34.6 \%$, and $26.0 \%$, respectively. Mangya and Tuole, located in the north of QTP, experienced relatively low wind speeds, with values peaking at $28.0-32.0 \mathrm{~m} / \mathrm{s}$ and wind speeds $>17.2 \mathrm{~m} / \mathrm{s}$ occurring $10.2 \%$ and $16.4 \%$ of the study period, respectively. Similarly, in the west of QTP, Shiquanhe also showed relatively low wind speeds, with wind speeds $>17.2 \mathrm{~m} / \mathrm{s}$ occurring 10.6\%. Other stations, such as Golmud, Yushu, Zoige, and Kangding, had low wind speeds and greatest wind speeds of $24.0-28.0 \mathrm{~m} / \mathrm{s}$, and wind speeds $>17.2 \mathrm{~m} / \mathrm{s}$ were rather infrequent, occurring just $1.7 \%, 4.3 \%, 3.0 \%$, and $8.1 \%$, respectively. Lhasa and Nyingchi, located in valleys of the QTP, had the lowest wind speeds among the 12 stations; their wind speeds peaked at $20.0-24.0 \mathrm{~m} / \mathrm{s}$ and wind speeds $>17.2 \mathrm{~m} / \mathrm{s}$ were rare $(0.9 \%$ and $0.2 \%$, respectively).

Each of these 12 frequency distributions followed a unimodal distribution; however, their shapes differed. The median daily extreme wind speeds of Wudaoliang, Tuotuohe, Kangding, Shiquanhe, and Amdo were relatively high, at 14.4, 15.3, 13.8, 13.3, and $14.3 \mathrm{~m} / \mathrm{s}$, respectively. By contrast, Mangya, Tuole, Golmud, Yushu, Zoige, Lhasa, and Nyingchi experienced low median values of $10.6,12.6,8.5,10.2,9.9,9.0$, and $9.4 \mathrm{~m} / \mathrm{s}$, respectively.
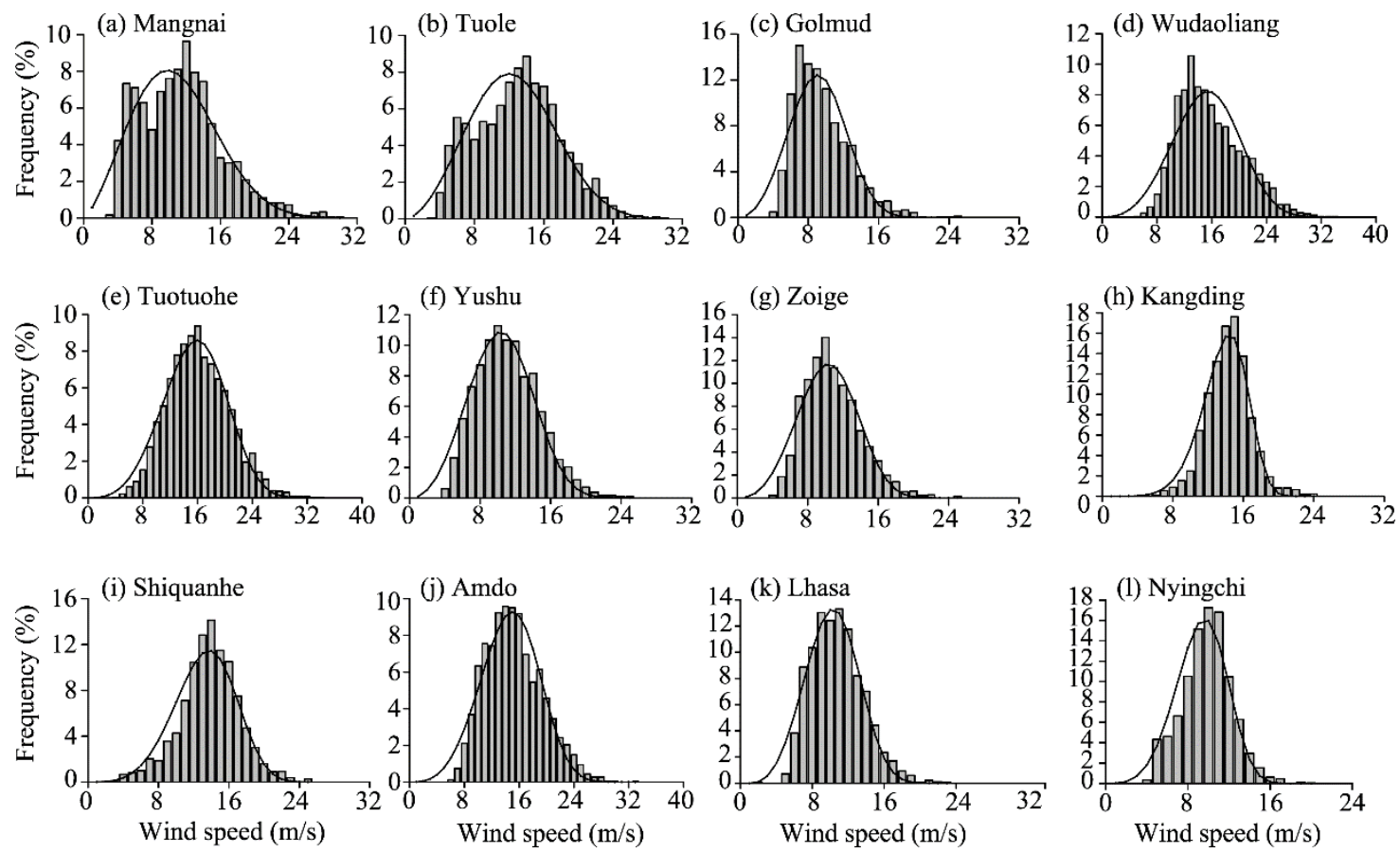

Fig. 5 Frequency distributions of daily extreme wind speeds with fitted curves for 12 typical stations

The wind speed distributions in these datasets were well represented by the Weibull distribution. The estimated Weibull parameters are given in Table 1. The three stations of Kangding, Shiquanhe, Nyingchi ranked the top three of the value of shape parameter while the Tuotuohe, Wudaoliang, Amdo ranked the top three of the value of scale parameter, respectively. 
Table 1 Weibull parameters for daily extreme wind gusts with fitted curves for 12 typical stations

\begin{tabular}{lccc}
\hline \multirow{2}{*}{ Station } & \multicolumn{3}{c}{ Parameter } \\
\cline { 2 - 4 } & $\alpha$ & $\beta$ & 0.0035 \\
Mangya & 2.419 & 12.227 & 0.0024 \\
Tuole & 2.808 & 14.042 & 0.0061 \\
Golmud & 3.253 & 10.148 & 0.0040 \\
Wudaoliang & 3.616 & 16.897 & 0.0009 \\
Tuotuohe & 3.884 & 17.198 & 0.0013 \\
Yushu & 3.246 & 11.595 & 0.0025 \\
Zoige & 3.473 & 11.435 & 0.0018 \\
Kangding & 6.337 & 14.839 & 0.0029 \\
Shiquanhe & 4.415 & 14.556 & 0.0017 \\
Amdo & 3.959 & 16.216 & 0.0017 \\
Lhasa & 3.542 & 10.232 & 0.0039 \\
Nyingchi & 4.359 & 10.208 & \\
\hline
\end{tabular}

Note: $\alpha$, shape parameter; $\beta$, scale parameter; Err, mean absolute error.

\subsection{Wind rose diagrams}

A wind rose depicts the frequency of winds occurring from each direction and also indicates the wind speed classes for a given location and time period. Since sand transport generally occurs at wind speeds greater than about $5.5 \mathrm{~m} / \mathrm{s}$, we incorporated wind speeds of less $5.5 \mathrm{~m} / \mathrm{s}$ into one class. All wind speeds are classified based on the Beaufort wind scale.

The wind roses of 12 typical stations are shown in Figure 6 and their extreme wind gusts were analyzed in detail. During the study period, Mangya showed multi-directional winds, mainly coming from the NE (15.8\%) and NW (12.2\%); however, wind speeds $>17.2 \mathrm{~m} / \mathrm{s}$ came from the NW (3.7\%) and WNW (3.3\%). Tuole had two wind directions and winds predominantly originating

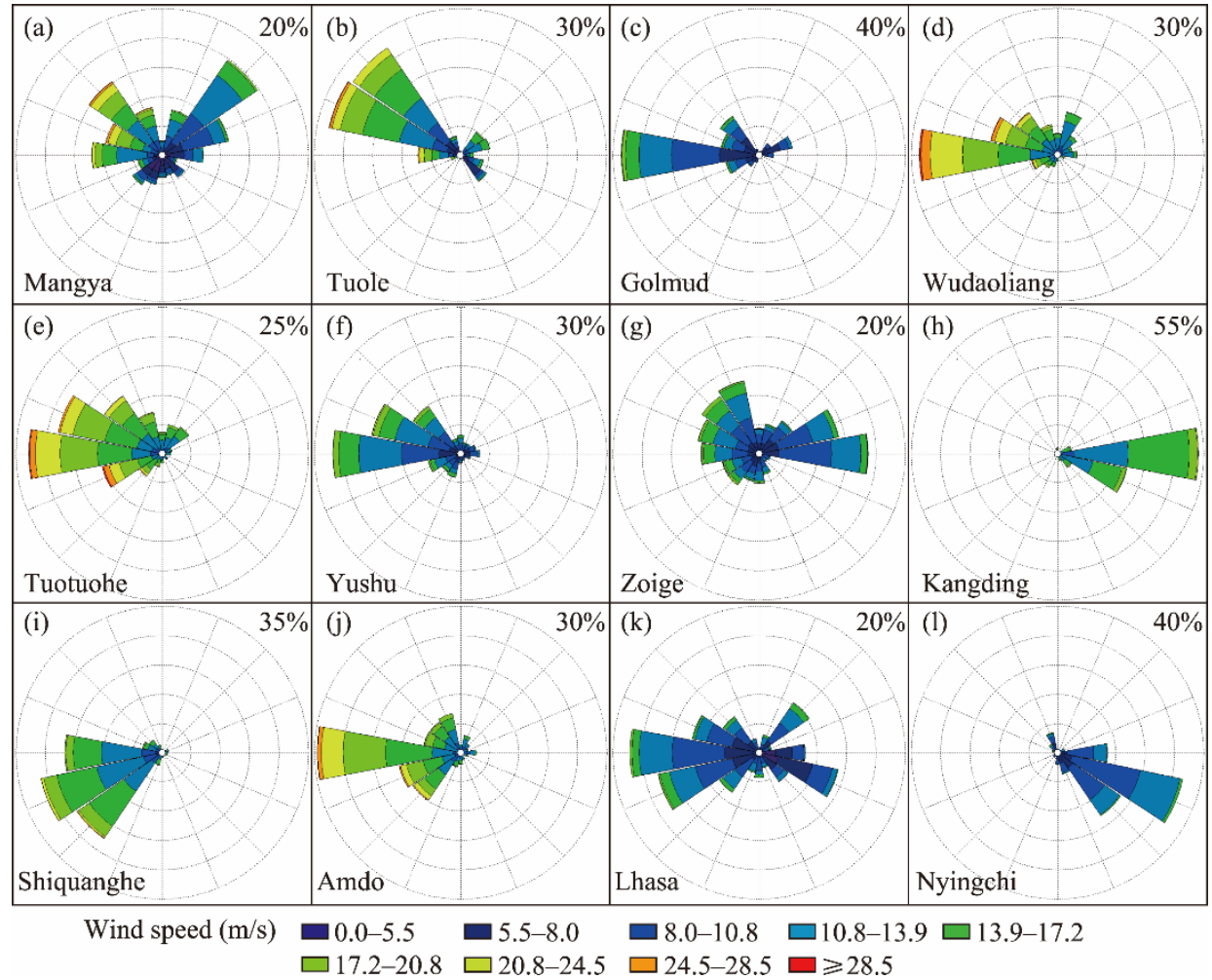

Fig. 6 Wind roses of the 12 typical stations on the QTP 
from the WNW (27.4\%) and NW (26.5\%) with wind speeds $>17.2 \mathrm{~m} / \mathrm{s}$ about $7.0 \%$ and $5.3 \%$, respectively. Golmud showed one prevailing wind direction of $\mathrm{W}(37.6 \%)$ and its wind speeds $>17.2 \mathrm{~m} / \mathrm{s}$ happened just $1.1 \%$, respectively. The main wind directions of gusts at Wudaoliang are from W (28.3\%) and NWW (13.0\%), in which they attained speeds of $>17.2 \mathrm{~m} / \mathrm{s}$ about $16.1 \%$ and $7.2 \%$, respectively. That wind rose also revealed a NNE wind component $(9.0 \%)$ with wind speeds in the $5.5-17.1 \mathrm{~m} / \mathrm{s}$ range $(8.8 \%)$. The Tuotuohe station had more variation in its wind directionality. Its winds originated primarily from the W $(22.7 \%)$, NWW $(18.1 \%)$, SWW $(12.0 \%)$, and NW (10.5\%); wind speeds from these directions $>17.2 \mathrm{~m} / \mathrm{s}$ prevailed $11.7 \%, 8.1 \%$, $6.1 \%$, and $3.6 \%$, respectively. Yushu showed three wind directions, of W (26.2\%), WNW (18.6\%), and NW (11.8\%), with wind speeds $>17.2 \mathrm{~m} / \mathrm{s}$ occurring $1.2 \%, 1.5 \%$, and $0.8 \%$, respectively. Zoige had multi-directional winds, with the main winds coming mostly from the E (14.9\%), ENE (11.1\%), and NNW (10.2\%); for these, wind speeds $>17.2 \mathrm{~m} / \mathrm{s}$ were very rare, reaching only $0.1 \%, 0.1 \%$, and $0.3 \%$, respectively. Kangding showed two wind directions, of E (52.9\%) and ESE (26.7\%), with wind speeds $>17.2 \mathrm{~m} / \mathrm{s}$ occurring $3.5 \%$ and $1.8 \%$, respectively. The main wind directions at Shiquanhe are from WSW (29.6\%), SW (24.7\%), and W (23.3\%). Wind speeds from these directions were $>17.2 \mathrm{~m} / \mathrm{s}$ about $3.9 \%, 3.6 \%$ and $2.0 \%$, respectively. The conditions at Amdo are similar to those at Wudaoliang. For both, their winds came mostly from W (29.4\%), SWW (12.9\%), and SW (11.8\%), and wind speeds $>17.2 \mathrm{~m} / \mathrm{s}$ from these directions occurred $14.0 \%, 5.0 \%$, and $2.8 \%$, respectively. Lhasa shows multi-directional winds; its main winds came mostly from the $\mathrm{W}$ (17.6\%), WSW (14.1\%), and ESE (11.1\%), respectively, all of which rarely reached $>17.2 \mathrm{~m} / \mathrm{s}$ (less than $0.3 \%)$, respectively. Nyingchi displayed three wind directions, of ESE (34.9\%), SE (20.9\%), and $\mathrm{E}(13.7 \%)$, but here the wind speeds did not exceed $17.2 \mathrm{~m} / \mathrm{s}$.

\subsection{Intra-annual variation in extreme wind gusts}

Variations in daily extreme wind speed at the 12 stations were strongly seasonal (Fig. 7). Not surprisingly, wind speeds were significantly higher in the windy season than at any other time of

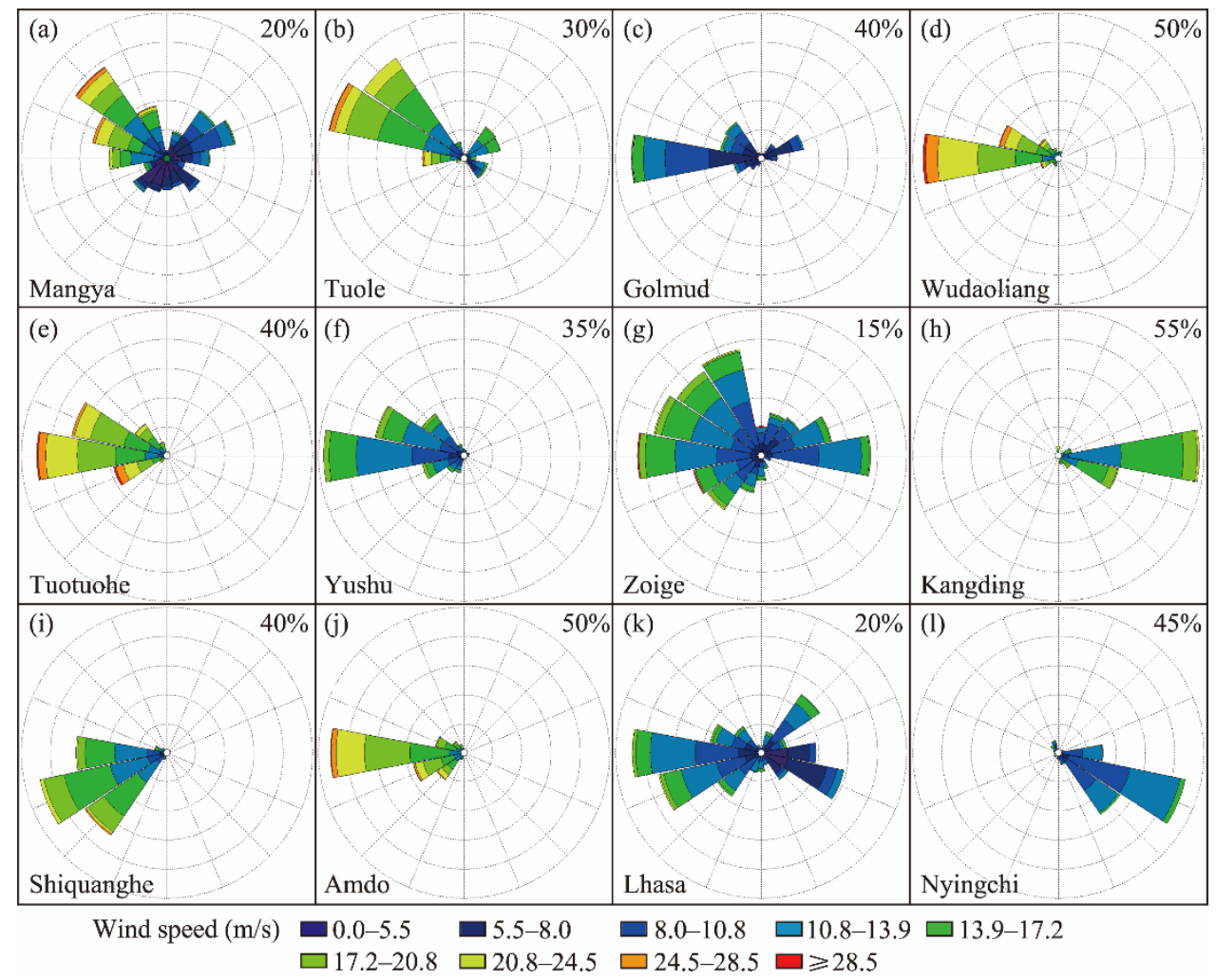

Fig. 7 Windy season wind roses of 12 typical stations on the QTP 
the year. Wind speed gusts $>17.2 \mathrm{~m} / \mathrm{s}$ occurred on 43.3, 68.2, 11.8, 127.9, 161.8, 21.5, 20.4, 65.2, 39.8, 123.2 12.8, and 9.8 d per year at Mangya, Tuole, Golmud, Wudaoliang, Tuotuohe, Yushu, Zoige, Kangding, Shiquanhe, Amdo, Lhasa, and Nyingchi, respectively. Although severe wind events $(>17.2 \mathrm{~m} / \mathrm{s})$ can occur in any month of the year, the highest frequency of severe wind events happened mostly from November to April (average speeds of 11.5, 14.3, 9.5, 17.5, 17.4, 11.4, 11.2, $14.6,13.6,16.8,9.7$, and $10.1 \mathrm{~m} / \mathrm{s}$, respectively, for the 12 stations above). Lower wind speeds occurred mostly from May to October (average speed of 10.0, 11.4, 8.2, 13.5, 14.3, 10.0, 9.6, 13.3, $13.0,13.0,8.9$, and $8.8 \mathrm{~m} / \mathrm{s}$, respectively). The proportion of wind gusts that had speeds of $>17.2$ $\mathrm{m} / \mathrm{s}$ during the windy season were respectively $12.2 \%, 23.0 \%, 2.6 \%, 53.3 \%, 54.0 \%, 4.6 \%, 4.2 \%$ $15.2 \%, 16.2 \%, 46.9 \% 1.8 \%$, and $0.3 \%$ at the 12 stations. At other times of the year, gusts $>17.2 \mathrm{~m} / \mathrm{s}$ occur in much lower proportions, at $8.8 \%, 11.6 \%, 0.4 \%, 15.1 \%, 20.8 \%, 4.1 \%, 2.1 \%, 3.1 \%, 6.5 \%$, $9.1 \%, 0.3 \%$, and $0.1 \%$, for the above 12 stations respectively.

During the windy season, winds came predominantly from one or two directions. At Mangya, Golmud, Wudaoliang, Kangding, Amdo, and Nyingchi, their wind roses during the windy season revealed one predominant direction of $\mathrm{NW}(15.2 \%), \mathrm{W}(35.5 \%), \mathrm{W}(46.4 \%), \mathrm{E}(53.1 \%), \mathrm{W}$ (45.8\%), and ESE (40.0\%), respectively. Tuole, Tuotuohe, and Yushu, showed two directions of WNW (28.4\%) and NW (25.0\%), W (35.7\%) and NWW (26.6\%), W (33.7\%), and WNW (21.8\%), respectively. Shiquanhe and Lhasa each displayed three wind directions: WSW (35.5\%), SW $(27.3 \%)$, W (25.0\%) and W (17.7\%), WSW (14.4\%), ESE (11.6\%), respectively. However, the winds at Zoige came from five directions: W (12.7\%), E (11.3\%), WNW (11.3\%), NNW (11.1\%), and NW (10.5\%).

Outside of the windy season, winds are multi-directional but some stations did show one or two directions (Fig. 8). In Wudaoliang, the three main directions were W (15.1\%), NW (12.3\%), and NNE (13.6\%) with two secondary directions of NWW (9.1\%) and NNW (8.4\%). In Tuotuohe, the three main directions were W (13.6\%), NW (12.9\%), and NWW (12.1\%) with three secondary directions of NWW (9.7\%), NE (8.7\%), and NNE (8.0\%). In Amdo, the main directions were W

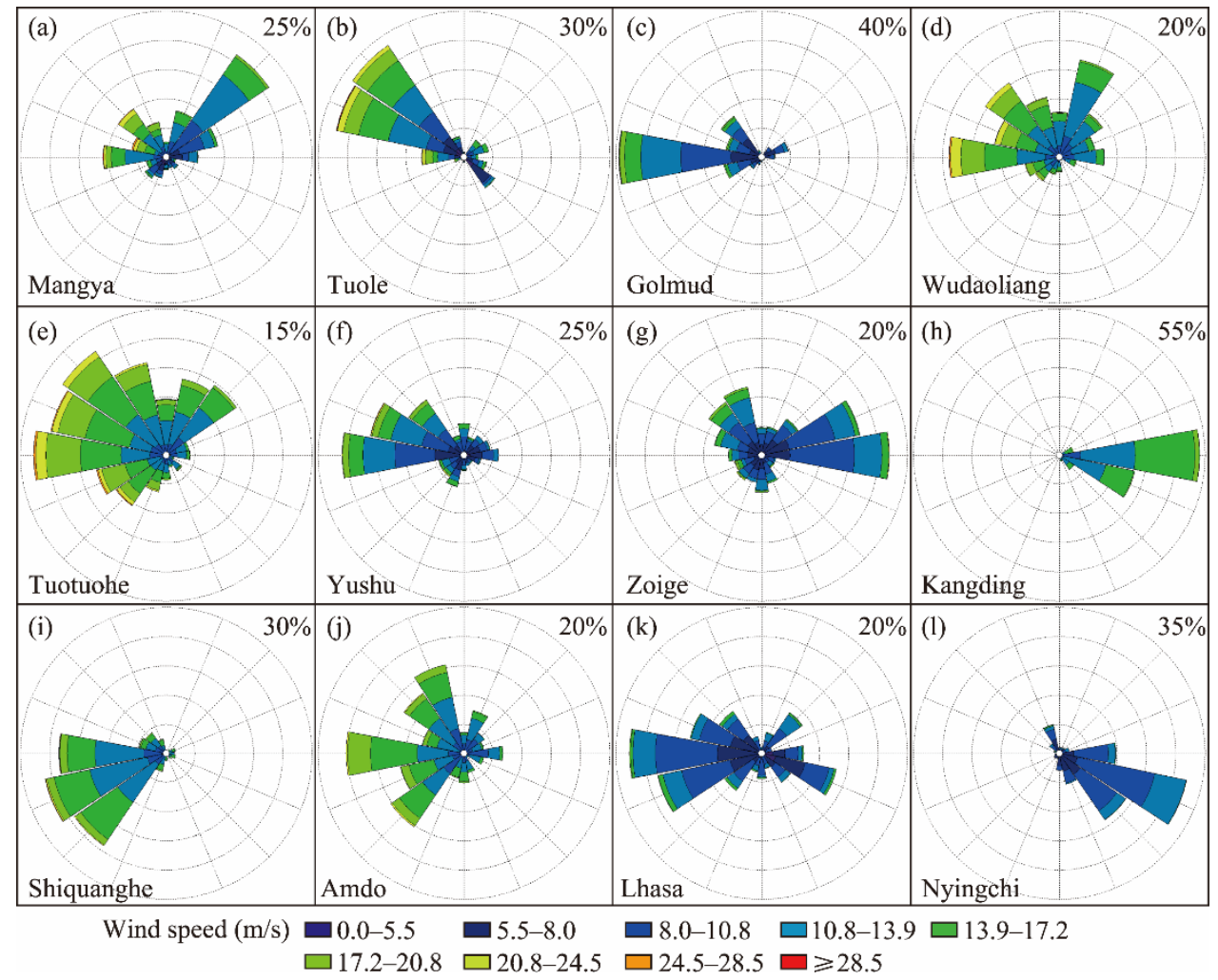

Fig. 8 Non-windy season wind roses of 12 typical stations on the QTP 
(16.1\%), NNW (12.4\%), and SW (12.2\%), along with two secondary directions of NW (10.0\%) and SSW (8.9\%). In Lhasa, the main directions were W (18.1\%) and WSW (14.6\%), with two secondary directions of ESE (10.5\%) and WNW (10.0\%). Yushu and Shiquanhe each showed three directions of W (20.8\%), WNW (16.4\%), NW (11.5\%) and SW (25.4\%), SW (22.9\%), W (22.1\%), respectively. Tuole, Zoige, Kangding, and Nyingchi each showed two directions of WNW (26.7\%) and NW (27.7\%), E (17.5\%) and ENE (13.8\%), E (52.8\%) and ESE (29.1\%), ESE (31.1\%) and SE (19.3\%), respectively. Mangya and Golmud each had one direction of NE (21.2\%) and W (39.1\%), respectively.

\subsection{Probability of extreme wind speeds}

Although the annual mean wind speed has generally decreased over time on the QTP, the annual maximum extreme wind speed has increased in some areas, especially at stations along the QinghaiTibet Railway. A changing climate and higher wind speeds may thus require heightened design standards to prevent increased damage to residential construction. Hence, determining the probability of extreme wind speeds on the QTP is critical for future development projects there.

By fitting the extreme value series for the annual maximum daily instantaneous wind speeds to a Gumbel distribution, using the steps outlined by Morjani (2011), we determined the annual maximum daily extreme wind speed for a range of return periods at three stations that might suffer severe wind damage. These results are presented in Table 2.

Table 2 Projected annual maximum daily extreme wind speed on the Qinghai-Tibet Plateau

\begin{tabular}{cccc}
\hline \multirow{2}{*}{ Return period (a) } & \multicolumn{2}{c}{ Annual maximum daily extreme wind speed (m/s) } \\
\cline { 2 - 4 } & Wudaoliang & Tuotuohe & Amdo \\
\hline 2 & 29.4 & 30.5 & 28.0 \\
10 & 31.2 & 31.9 & 29.9 \\
20 & 32.4 & 32.7 & 31.1 \\
50 & 33.5 & 33.5 & 32.2 \\
100 & 34.9 & 34.6 & 33.7 \\
\hline
\end{tabular}

Note: The predictions are based on very short data records (seven or nine years per station). As more data becomes available, extrapolations for the high return periods should become more accurate.

\section{Conclusions}

This study determined the characteristics of daily extreme wind regimes on the QTP in China based on 5 years of continuous data from 95 meteorological stations. Overall, during the period 20082012, the QTP experienced frequent occurrences of extreme winds with gusts of $17.2 \mathrm{~m} / \mathrm{s}$ or greater. Wind speeds at three stations along the Qinghai-Tibet Railway, i.e. Wudaoliang, Tuotuohe and Amdo, were significantly higher (annual maximum daily extreme wind speeds of 30.9, 33.0 and $32.2 \mathrm{~m} / \mathrm{s}$, respectively) than those recorded at stations in neighboring areas.

The seasonal distribution of the wind is clearly confirmed. The vast majority of extreme winds on the QTP happen during the windy season, from November to April, when more than 53.3\%, $54.0 \%$, and $46.90 \%$ of the severe winds occurred at the stations of Wudaoliang, Tuotuohe, Amdo, respectively. Gusts with wind speeds greater than $17.2 \mathrm{~m} / \mathrm{s}$ occurred $114.2,126.3$, and $95.0 \mathrm{~d}$ per year at the three railway stations above, respectively.

The terrain effect is prominent on the QTP. Spatial analysis of the wind speed data showed that wind speeds increased exponentially with the increasing altitude. The return periods for wind gust speeds were obtained using the application of statistical extreme value distributions. We analyzed the probability of extreme wind speeds using the Gumbel model, and calculated annual maximum daily extreme wind speed values for the stations of Wudaoliang, Tuotuohe, Amdoover desired return periods. For a return period of 50 years, annual maximum daily extreme wind speeds of 34.9, 34.6 and $33.7 \mathrm{~m} / \mathrm{s}$, respectively, can be expected at the three stations.

Additional attention should be given to those stations where yearly maximum daily extreme wind 
speeds increased at a rate greater than that of mean value of daily extreme wind speed. These stations are located mainly in the Qaidam Basin and along the Golmud-Lhasa section of the Qinghai-Tibet Railway. We predict that severe extreme wind events in these regions are likely to become more frequent. Consequently, building designers in these areas should use updated extreme wind data in their structural design work rather than only relying on past data.

\section{Acknowledgements}

This work was funded by the Ministry of Science and Technology of the People's Republic of China (2013CB956000) and the Natural Science Foundation of Gansu Province (1606RJZA142). We also thank the anonymous reviewers and the editor for their insightful comments and suggestions.

\section{References}

Bai H Z, Dong A X, Li D L, et al. 2005. Temporal and spatial characteristics of strong wind and dust days in Qinghai-Xizang Plateau and along Qingzang Railway. Plateau Meteorology, 24(3): 311-315. (in Chinese)

Boos W R, Kuang Z M. 2010. Dominant control of the South Asian monsoon by orographic insulation versus plateau heating. Nature, 463(7278): 218-222.

Boos W R, Kuang Z M. 2013. Sensitivity of the South Asian monsoon to elevated and non-elevated heating. Scientific Reports, 3: $1192-1195$.

Carta J A, Ramírez P. 2007. Analysis of two-component mixture Weibull statistics for estimation of wind speed distributions. Renewable Energy, 32(3): 518-531.

Carta J A, Ramírez P, Velázquez S. 2009. A review of wind speed probability distributions used in wind energy analysis. Renewable and Sustainable Energy Reviews, 13(5): 933-955.

Chen Y F, Gao G. 2010. An analysis to losses caused by meteorological disasters in China during 1989-2008. Meteorological Monthly, 36(2): 76-80. (in Chinese)

Datta R, Ranganathan V T. 2003. A method of tracking the peak power points for a variable speed wind energy conversion system. IEEE Transactions on Energy Conversion, 18(1): 163-168.

Fang X M, Han Y X, Ma J H, et al. 2004. Dust storms and loess accumulation on the Tibetan Plateau: A case study of dust event on 4 March 2003 in Lhasa. Chinese Science Bulletin, 49(9): 953-960.

Goldstein J, Langlois J D, Dimitrijevic M, et al. 2008. Approaches for extreme wind speed assessment: a case study. In: Proceedings of the $7^{\text {th }}$ World Wind Energy Conference 2008. Kingston: Ontario, Helimax Energy Inc.

Han Y, Fang X, Kang S, et al. 2008. Shifts of dust source regions over central Asia and the Tibetan Plateau: Connections with the Arctic oscillation and the westerly jet. Atmospheric Environment, 42(10): 2358-2368.

Ju K Y. 2012. Primary analysis on loss of meteorological disaster in Qinghai Province in recent 27a. Journal of Qinghai Meteorology, 3: 2-5. (in Chinese)

Kiss P, Jánosi I M. 2008. Comprehensive empirical analysis of ERA-40 surface wind speed distribution over Europe. Energy Conversion and Management, 49(8): 2142-2151.

Larsson A. 2002. Flicker emission of wind turbines during continuous operation. IEEE Transactions on Energy Conversion, 17(1): 114-118.

Li J C, Liu H X, Su Z Z, et al. 2015. Changes in wind activity from 1957 to 2011 and their possible influence on aeolian desertification in northern China. Journal of Arid Land, 7(6): 755-764.

Liu X D, Dong B W. 2013. Influence of the Tibetan Plateau uplift on the Asian monsoon-arid environment evolution. Chinese Science Bulletin, 58(34): 4277-4291.

Lun I Y F, Lam J C. 2000. A study of Weibull parameters using long-term wind observations. Renewable Energy, 20(2): 145153.

Luo S Z, Wang Q C, Dai S. 2012. An analysis of climate characteristics of meteorological disasters in Qinghai Province. Journal of Glaciology and Geocryology, 34(6): 1380-1387. (in Chinese)

Monahan A H. 2007. Empirical models of the probability distribution of sea surface wind speeds. Journal of Climate, 20: 57985814.

Morjani Z E A A E. 2011. Wind Speed Hazard Modelling. Methodology document for the WHO e-atlas of disaster risk. Volume 1. Exposure to natural hazards Version 2.0. Agadir: Morocco Taroudant Poly-Disciplinary Faculty of the Ibn Zohr University of Agadir Press, 10-14. 
Qiu J. 2008. China: The third pole. Nature, 454: 393-396.

Razali A M, Salih A A, Mahdi A A. 2009. Estimation accuracy of Weibull distribution parameters. Journal of Applied Sciences Research, 5(7): 790-795.

Rocha P A C, de Sousa R C, de Andrade C F, et al. 2012. Comparison of seven numerical methods for determining Weibull parameters for wind energy generation in the northeast region of Brazil. Applied Energy, 89(1): 395-400.

Seguro J V, Lambert T W. 2000. Modern estimation of the parameters of the Weibull wind speed distribution for wind energy analysis. Journal of Wind Engineering and Industrial Aerodynamics, 85(1): 75-84.

Shi P J. 2003. Atlas of Natural Disaster System of China. Beijing: Science Press, 170-172. (in Chinese)

Stewart D A, Essenwanger O M. 1978. Frequency distribution of wind speed near the surface. Journal of Applied Meteorology and Climatology, 17: 1633-1642.

Tye M R, Stephenson D B, Holland G J, et al. 2014. A Weibull approach for improving climate model projections of tropical cyclone wind-speed distributions. Journal of Climate, 27: 6119-6133.

Waylen P, Woo M. 1982. Prediction of annual floods generated by mixed processes. Water Resources Research, 18(4): 12831286.

Xie S B, Qu J J, Lai Y M, et al. 2015. Effects of freeze-thaw cycles on soil mechanical and physical properties in the QinghaiTibet Plateau. Journal of Mountain Science, 12(4): 999-1009.

Ye D Z, Gao Y X. 1979. Climatology of the Qinghai-Tibetan Plateau. Beijing: Science Press, 49-59. (in Chinese)

Zhang K C, Qu J J, Han Q J. 2012. Wind energy environments and aeolian sand characteristics along the Qinghai-Tibet Railway, China. Sedimentary Geology, 273-274: 91-96.

Zhou Y, Guo B, Wang S X, et al. 2015. An estimation method of soil wind erosion in Inner Mongolia of China based on geographic information system and remote sensing. Journal of Arid Land, 7(3): 304-317. 